\title{
Extreme storm loading on in-service wharf structures
}

\section{Interest of monitoring for reliability updating}

\section{Humberto Yáñez-Godoy — Franck Schoefs \\ Anthony Nouy — Pascal Casari}

\section{Université de Nantes}

Institut de recherche en génie civil et mécanique (GeM)

CNRS UMR 6183, Faculté des Sciences et Techniques

2, rue de la Houssinière, F-44000 Nantes

\{humberto.yanez,franck.schoefs\}@univ-nantes.fr

ABSTRACT. Reliability of existing structures with large building uncertainties is a very difficult task. This paper aims to show how the data from structural monitoring and a fine mechanical analysis allows to update hypothesis on basic variables and reliability computation. The illustration concerns on-pile wharf which cranes are submitted to extreme storm loading.

RÉSUMÉ. La fiabilité des structures existantes présentant des aléas de mise en ouvre importants est un sujet difficile. Cet article montre comment des données d'instrumentation et une analyse mécanique détaillée des structures permet une mise à jour des hypothèses sur les variables de base puis des calculs de fiabilité. L'objet d'application est une structure portuaire de type quai sur pieu dont les portiques sont soumis à des chargements de tempête. KEYWORDS : storm loading, reliability, instrumentation, wharf. MOTS-CLÉs : actions de tempête, fiabilité, instrumentation, quai. 


\section{Introduction}

Harbour structures such as wharves are designed under vertical loading situations (self-weight, storage, weight of cranes) and also horizontal (docking/mooring of ships, wind on cranes). Storms conditions play a dominant role in this last case as they act on cranes (see Figure 1); they are of major importance for re-analysis of old structures which were designed without taking these situations into account. Moreover, with the possible climatic changes, there is a need of updating extreme wind speed and corresponding storm loading on structures in view to analyse the relative change in safety level. Reliability analysis gives efficient tools needed to perform such computations if boundary conditions are known with a given uncertainty. In case of large structures where the soil plays a dominant role, the complexity of boundary conditions is still unknown for in-service behaviour. Monitoring is then the only way for modelling. When scatter is high, probabilistic mechanics gives an efficient way to introduce randomness in analyses. This paper aims to provide a complete method to introduce information coming from monitoring as well as storm loading in reliability assessment.

The second section gives a brief presentation of the studied wharf and its instrumentation. The third section focuses on the data collection for the reliability analysis. First, probabilistic description of hazards during building stage and inservice behaviour is proposed on the basis of data from monitoring. To this aim, the discrete stochastic field of loading in anchoring rods is described by an analysis of its trajectories with space and time. A time interval is chosen where the field is stationary (with respect to time) in view to analyse the effect of various tide levels and to identify probabilistic models parameters. The role of a technological gap in the link between rod and behind-wall is underlined, which is the source of randomness in measured loading. This third section ends with the modelling of the storm loading on cranes through physical response surface methodology (Schoefs, 1996): they result from expansion of physical laws to the probabilistic context, in transferring wind kinematics field through suitable deterministic physical models. Section 4 deals with the identification of the non-linear model parameters for "soilrod-anchorage" complex behaviour through an inverse analysis based on the simplex method (method of zero order).

The paper ends with reliability analysis of an on pile wharf submitted to storms. A performantial criterion, based on wharf displacement and in line with the socalled Service-Limit-States is suggested to this aim. Sensitivity studies are then performed to rank the set of basic variables (tie-rods stiffness, wind speed) and to analyse the effect of the choice of the critical value of the performantial criterion. 


\section{Presentation of the studied structure and its monitoring}

\subsection{Technological description of the wharf}

Wharves are harbours structures which are dedicated to ships docking and stocking of containers for goods. The wharf studied here is called TMDC 4 (terminal for various goods and containers). It has been designed for big tonnage ships $(50000 \mathrm{~T})$, as over-panamax with a maximum draught of $14 \mathrm{~m}$ and is located near the sea, on the north bank at the mouth of the river Loire, about 2 kilometres downstream from Saint-Nazaire city, France. It is built on piles driven in the ground through more than 40 meters depths of sludge, silt and sand. A picture of this wharf during its building is shown in Figure 1 and a sketch of its section is shown on Figure 2. The main design concept is to distinguish the ability of the structure to carry vertical and transversal loads. It generally leads to the best compromise between technology and cost: as an example, tie-rods are dedicated to bear a high part of transverse loading (ship mooring...) and allows keeping pile diameter in a reasonable range in terms of beating power.

It is made up of a reinforced concrete deck of $250 \mathrm{~m}$ long and $43 \mathrm{~m}$ wide with a triangular network of reinforced concrete beams $0.75 \mathrm{~m}$ high and a reinforced dam $0.25 \mathrm{~m}$ thick. At each node of this network, a steel pile is filled up with concrete. The total is 332 piles with diameters varying from 0.711 to $0.914 \mathrm{~m}$ and steel thickness from 10.3 to $12 \mathrm{~mm}$ depending of the pile's location. They are beaten down to the rock deck at around $45 \mathrm{~m}$ deep. The function of this platform is to support vertical loading of containers, a mobile crane (335 tons) and cranes (1 100 tons). The wharf is leaned against a vertical reinforced concrete wall ("backwharf wall") $4.35 \mathrm{~m}$ high. It is dedicated to embankment loading: The embankment ballast is $0 / 180 \mathrm{~mm}$. Under this wall, a vertical sheet pile $4.5 \mathrm{~m}$ high prevents small soil particles from leaking. The role of the platform is also to average horizontal loading due to embankment and ship mooring which can not totally pass through the lateral capacity of piles. For this reason, the wharf is anchored inside the bank by 38 steel rods $(8.5 \mathrm{~mm}$ diameter and $20 \mathrm{~m}$ long). At their ends, tie-rods are clamped between the back-wharf wall and a vertical reinforced concrete anchoring plate embedded in the bank. An explaining diagram shows the architecture of the structure in Figure 2.

\subsection{Main building stages}

The building lasted 16 months, from November 2000 to February 2002. The several building stages, realized progressively from upstream to downstream are: preliminary earthworks with installation of embedding in downstream area (micropiles surmounted by reinforced slabs), pile beating, sheet pile beating (to avoid the leakage of fine soil particles from embankment), the construction of the back-wharfwall, the putting up of the capitals on top of the piles and connection of the 
prefabricated components (beams and slabs), tie-rods lying and embankment works, final earthworks and port facilities installation. Figure 1 shows some of these main steps: pile concreting, putting up of the capitals and the triangular slabs and connection of the beams on capitals before concreting of the back-wharf-wall.
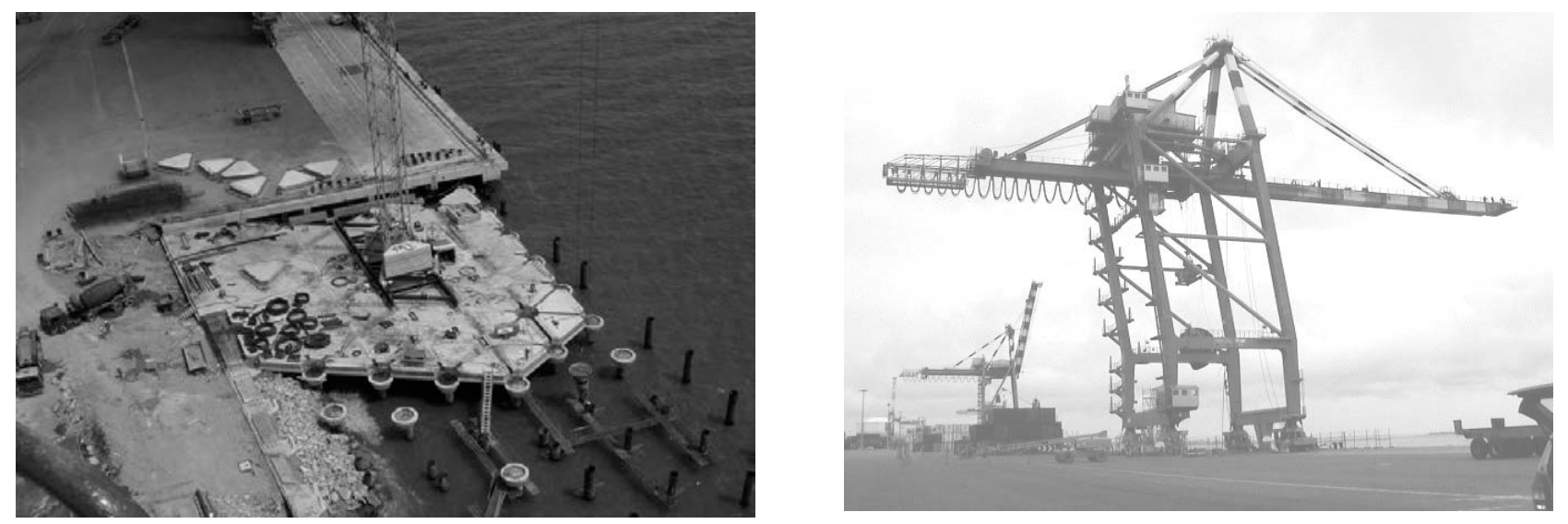

Figure 1. Aerial view of the wharf and a picture of the crane

\subsection{Design methods and main hypotheses}

Only quasi-static behaviour is considered for designing these wharfs. The loading situations include:

- vertical loading coming from self weighting and storage and cranes,

- horizontal loading due to embankment loading on the back-wharf-wall, ship berthing, ship mooring and wind actions on cranes and ships.

The main hypotheses, which are generally assumed, come from expert judgment and uncertainty studies performed during preparation of European semi-probabilistic code format called Eurocode 7 (de Grave, 2002). Judgment of expert of wharf design leads to several analyses:

- tie-rods are pre-stressed and are loaded by the platform depending of the platform deformation only,

- immediately after construction, loading on the vertical reinforced concrete anchoring plate embedded inside the bank are sufficient to assume that the passive earth pressure is totally acting: limit state is reached.

More details can be found in (Verdure, 2004). We focus here on loadings where hazards and uncertainties are more important: horizontal loadings and especially the one acting from the bank to the river. In fact, this loading is the source of the most sensitive damages in structures, particularly the relative displacement between the platform and the embankment. Ship mooring is here neglected but can be introduced in the same way as wind loading. When considering the corresponding loading situation, mainly tie-rods and lateral capacity of piles are loaded. Due to the high stiffness of the platform, studies have shown a great variance reduction: hazards on 
pile behaviour, assumed un-correlated, are then slightly transferred. Only a rich data base and a great correlation length could call this hypothesis into question. Similarly for earth pressure, the variance is reduced or even cancelled due to the high inertia of the back-wharf-wall. More details and related sensitivity studies are given in (Verdure et al., 2005). On the other hand, a great hazard lies in the computation of storm loading on cranes and in rod behaviour. That is why a monitoring of the tierods has been carried out during building.

\subsection{Instrumentation}

The wharf is instrumented with two kinds of sensors (shown in Figure 2).

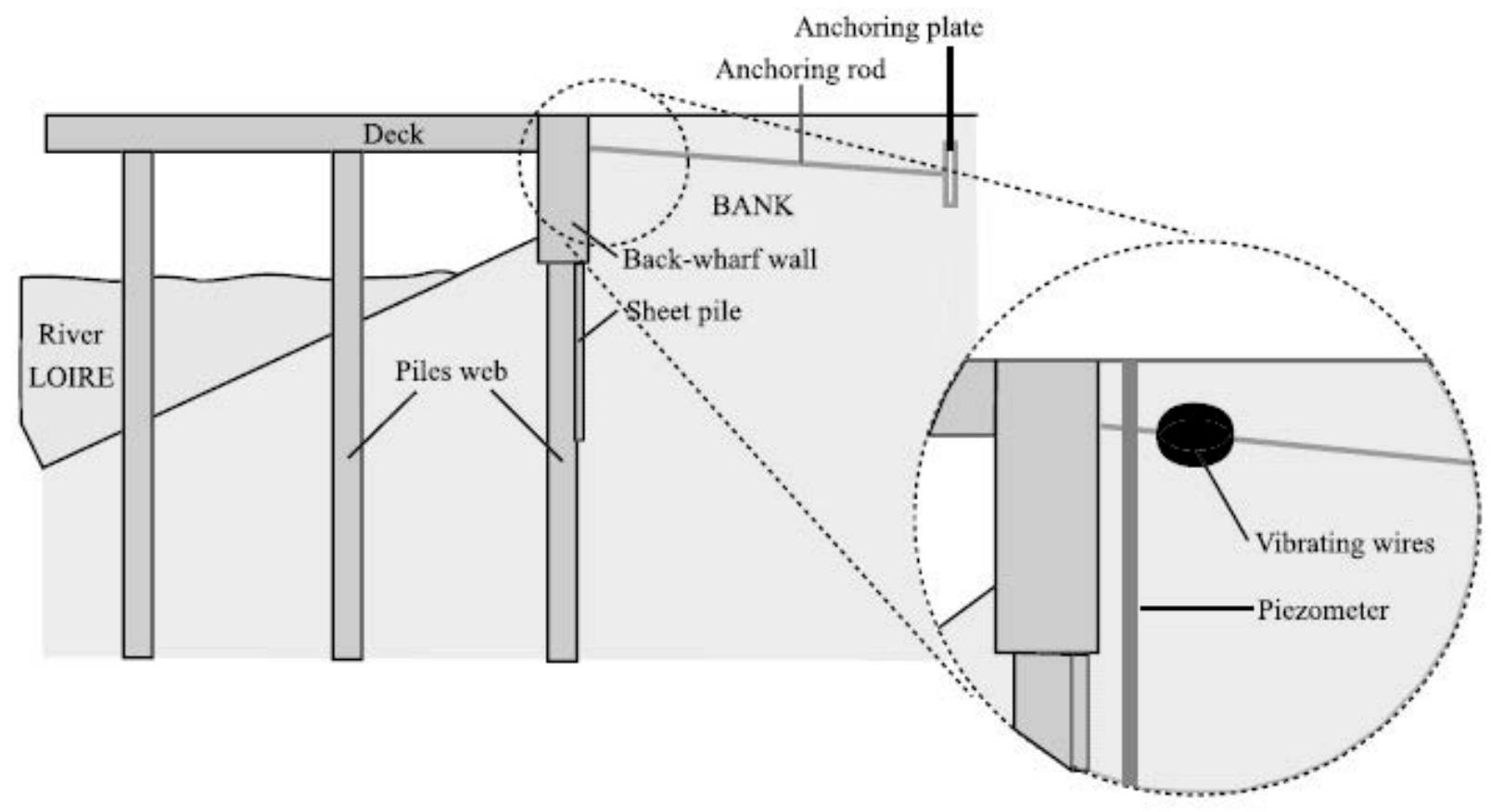

Figure 2. Sketch of a wharf section

A set of 12 couples of vibrating wire sensors (WR) clamped on the anchoring rods are regularly spaced out: the use of two sensors in the same cross section, one on top and one at the bottom, allows the measurement of the normal load and the bending moment. Only normal load is used in the following. Instrumented tie-rods are the end ones (upstream and downstream), and 10 regularly distributed ones along the wharf. They are classified with their distance $x$ along the wharf, from upstream $(x=0)$ to downstream $(x=250 \mathrm{~m})$. Tie-rods at the ends are instrumented in three sections in order to analyse the effect of soil along the rod (see Figure 3).

One piezometer, located inside the bank, in the middle of the wharf, is used to measure the water level. Thus, knowing the actual sea level in the river Loire provided by the port services, the difference between the levels in the sea and in the bank can be deduced. 
The measures are recorded every 30 minutes with a "Campbell Scientific CR10X" data logger. This period is relevant for the description of periodic processes like tide affecting the mechanical response of the structure (approximately 12 hours periodic). The same period of data storage was used at the Container Terminal Altenwerder, in the port of Hamburg, which is another instrumented on-pile wharf, built with quite the same technology (Gattermann et al., 2001). Data have been recorded since the $1^{\text {st }}$ of October 2002. The number of sensors has been determined for cost reasons and also to get a satisfactory confidence in the estimate of mean and standard deviation of measurements.

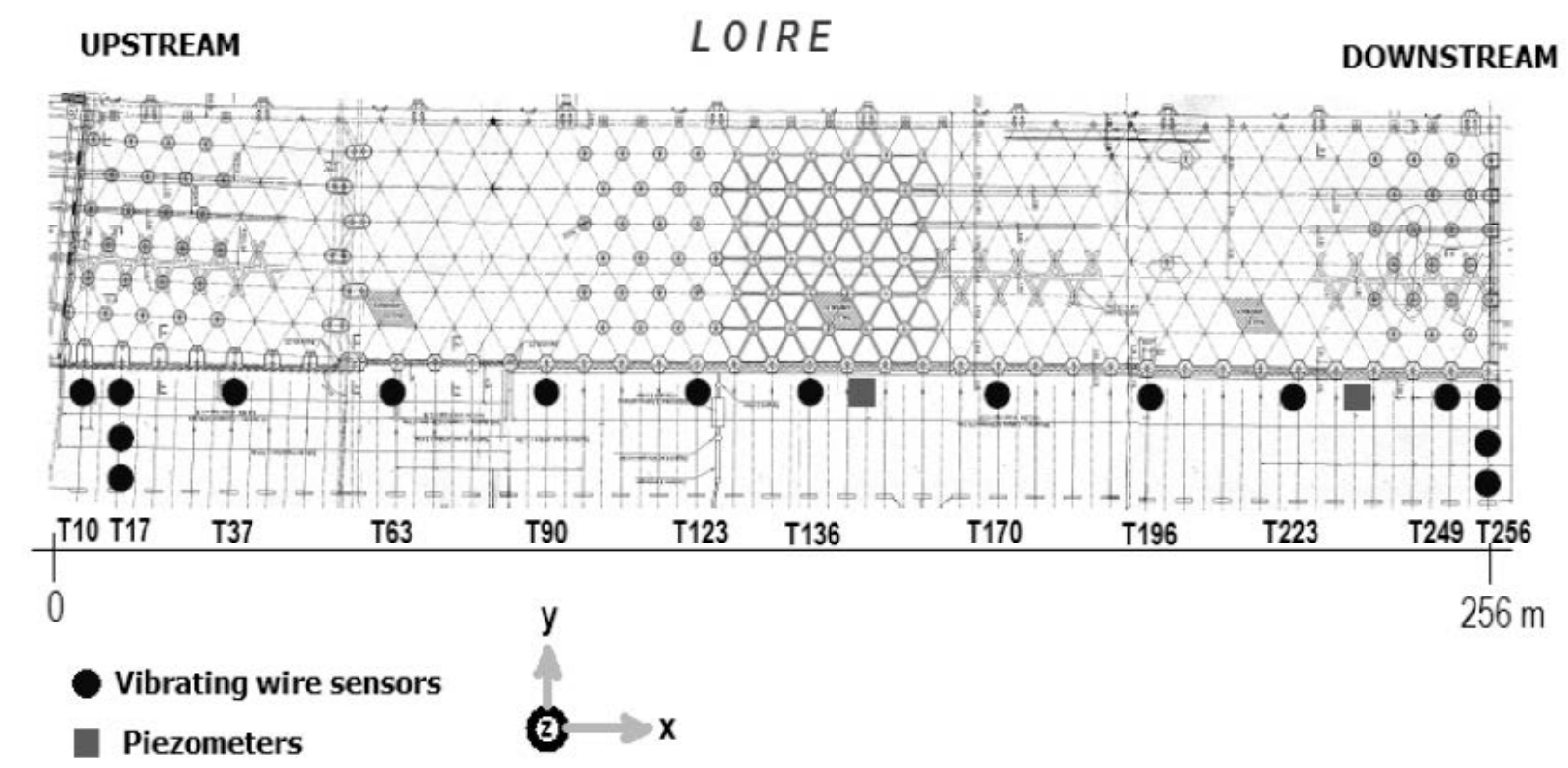

Figure 3. View of instrumentation plan of the wharf

\section{Data collection for reliability computation updating}

\subsection{Results of monitoring and probabilistic modelling of the behaviour of the set "soil-rod-anchorage plate"}

The modelling of passive tie-rods behaviour in embankment is still a challenge. Some finite element calculations allow answering partially once given parameters which are difficult to identify. With the monitoring we aim to characterize a more global behaviour, which concerns the set "soil-rod-anchorage plate". This reduction of complexity allows introducing boundary conditions in structural reliability analysis but the question of the real non-linear behaviour remains. Several levels of statistical analysis are then needed which can be asked as follows:

- what is the spatial distribution of loading?

- what is the role of tide level?

- what is the stochastic structure in space and time of discrete stochastic field "loading in tie-rods"? 
An analysis of data collected in the first three years shows two stages of behaviour: the first one is characterized by its stochastic structure in time with no apparent correlation and the second one begins after two years with a significant correlation with time but which is still an object of study. This paper focuses on the first stage. Note that these data do not include any storm event. Among the results (Verdure et al., 2003; Verdure, 2004), we observed a great scatter in space and time:

- of profiles of loading in tie-rods along the wharf,

- of tie-rods sensitivity to tide level.

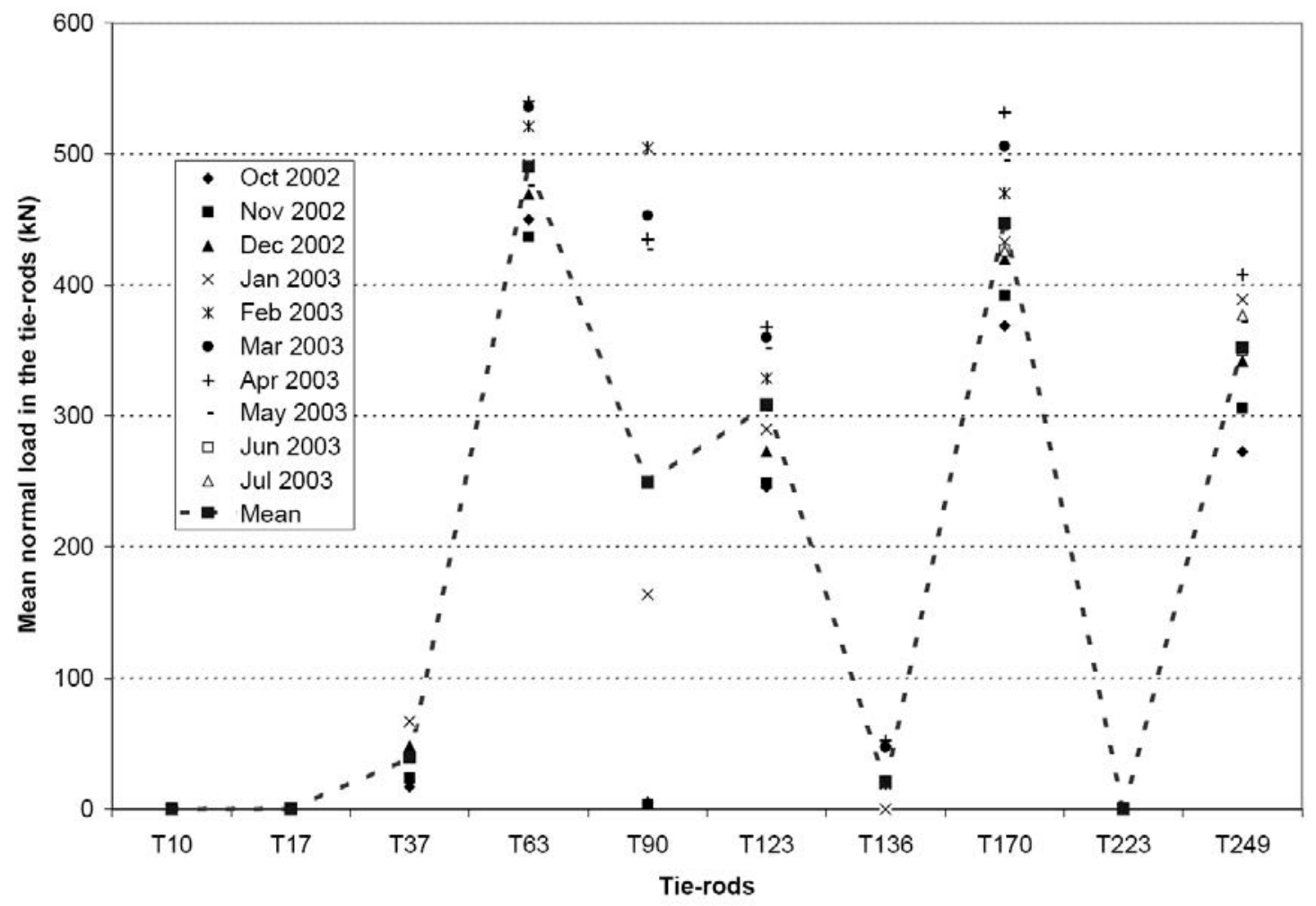

Figure 4. Variation of measured load in the tie-rods, phase 1, for several dates
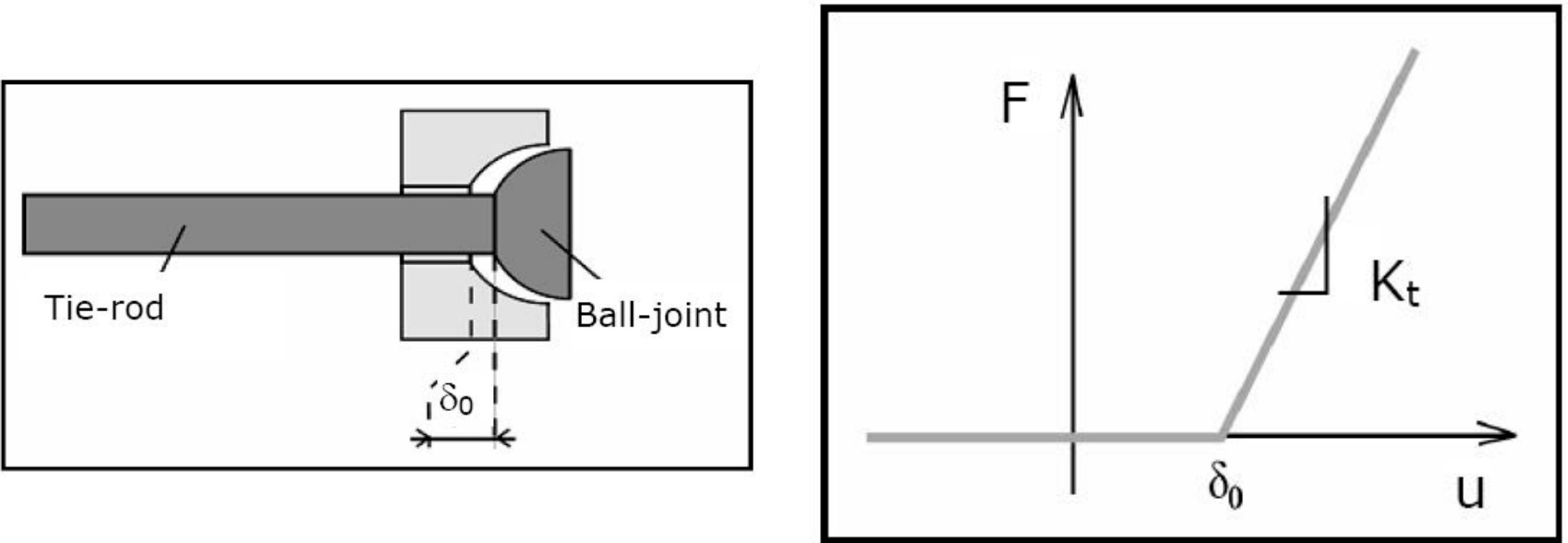

Figure 5. Sketch of the ball-joint in the back-wharf wall and its respective mechanical model 
The first point refers to section 2.2 about the embankment building with several stages and to the great scatter of methods for tie-rods installation. These events are the source of the fair spatial correlation of the profile of loading along the wharf. Figure 4 illustrates this point with a representation of several profiles obtained at given dates. Moreover, one must discuss the choice of the technological device to assure the anchorage of the back-wharf-wall: for momentum limitation, a ball-joint is selected (see Figure 5). If the rod is insufficiently initially loaded, the gap, initially full of mud and silt should lead to very light loads in case of wharf displacement. If we consider now effect of time, we assume that we have during this first stage a white-noise type process. Profiles are then computed for each month in view to smooth effects of the lunar period: each mean value calculated from a month period corresponds to a draw of loads independent of the previous.

The distribution density of monthly mean loads is plotted on Figure 6. We choose a bi-modal [1] probabilistic representation $f(x)$ for the corresponding law.

$$
f(x)=0.50 \delta(0)+0.50 \sigma^{-1} \exp \left(\frac{x-\mu}{v}\right) \exp \left(-\exp \left(\frac{x-\mu}{v}\right)\right)
$$

where $\delta$ denotes the dirac function.

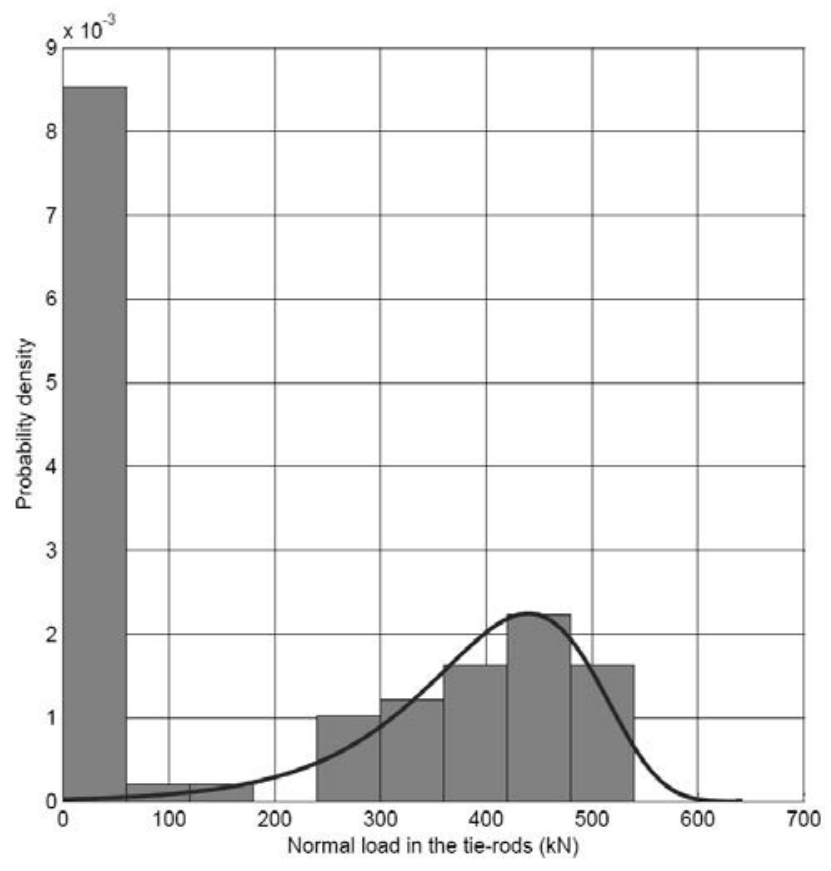

Figure 6. Histogram of the normal load in the tie-rods during stage 1

We assume here that loading is equal to 0 if under $20 \mathrm{kN}$, which corresponds to an upper-bound of measure uncertainty; the associated probability is 0.50 . Loading in other rods (loaded rods) follows an extreme value distribution, selected among a set of laws from maximum likelihood. Its parameters are deduced from this 
technique implemented in Matlab software; $\mu=440[\mathrm{kN}]$ and $v=80[\mathrm{kN}]$, corresponding to a mean value of $394[\mathrm{kN}]$ and a standard deviation of $103[\mathrm{kN}]$. Note that statistics directly deduced from analysis of loaded rods are 393 [kN] for $m_{\text {Fmes }}$ and $104[\mathrm{kN}]$ for $\sigma_{\text {Fmes. }}$

The second point (tie-rods sensitivity to tide level) is directly linked to stiffness of "soil-rod-anchorage plate". We've shown (Yáñez-Godoy, 2004) that in presence of high tide coefficients, up to 90, the behaviour of each rod can be represented by a sensitivity coefficient to the tide defined as the ratio between the loading variation during a tide and the corresponding variation of water level in the embankment. Here, storm conditions occur generally in winter were tide coefficients are high and we analyse in the following data obtained for a tide coefficient of 94, under the same hypothesis of white noise stochastic process. Profiles of load increasing during such tide are plotted in Figure 7 and the corresponding probability density in Figure 8 (log-normal distribution).

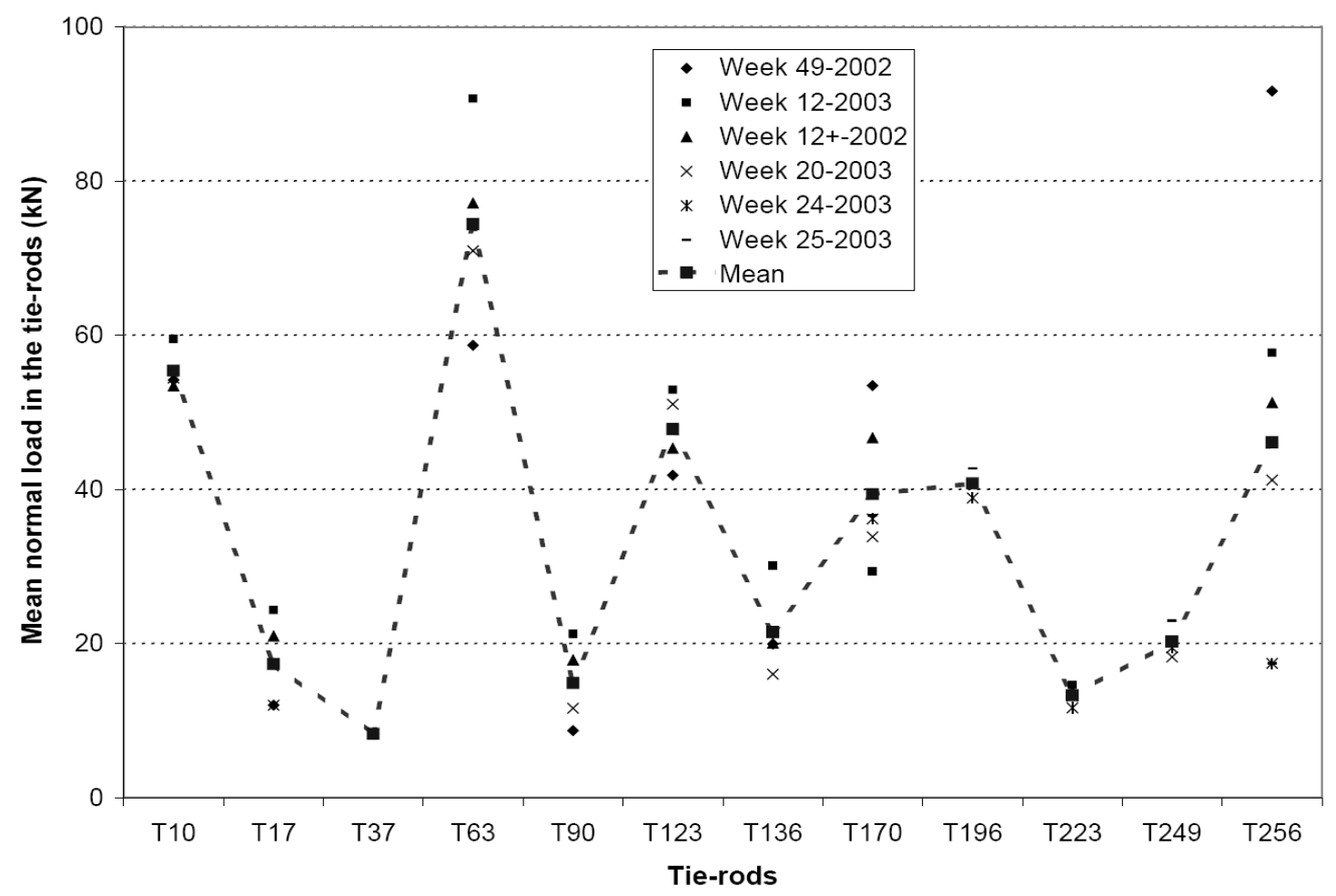

Figure 7. Variation of measured load in the tie-rods, phase 1, for several rising tides

To represent this hazard in terms of embankment loading (slack tide) and sensitivity during a tide, we select a one-side behaviour law for the set "soil-rodanchorage plate" with a cable model, which behaviour law is drawn in Figure 5 where $F$ denotes axial load and $u$ axial displacement. $K_{t}$ is the overall stiffness of rod-soil. $\delta_{0}$ is the gap in the ball-joint. 


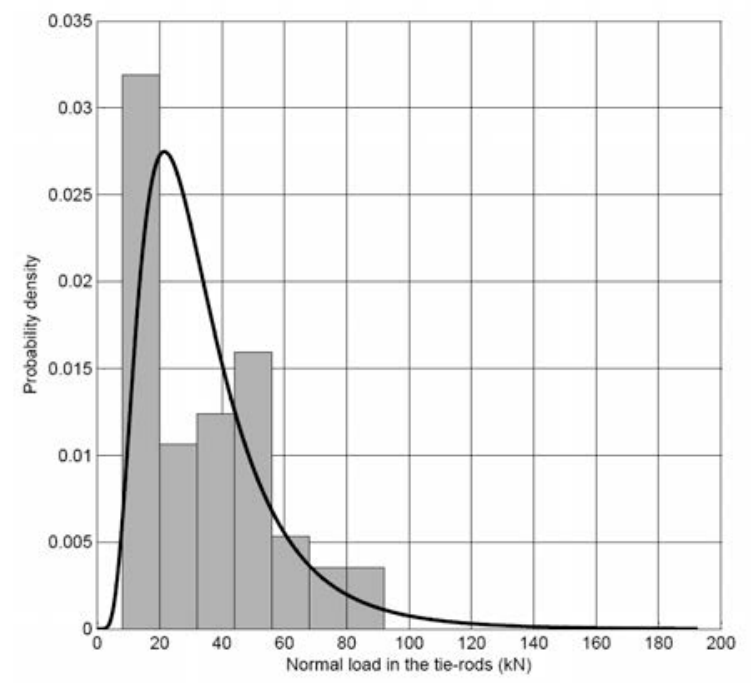

Figure 8. Histogram of the normal load in the tie-rods, phase 1, for several rising tides

\subsection{Storm conditions and wind loading modelling}

Here, gust of wind are considered: they are defined as the highest daily wind speed deduced from quasi-instantaneous ( $3 \mathrm{~s}$ ) measurements with an anemometer. The stochastic field of wind velocity is based on both statistical analysis of wind velocity data at height of 10 meters (reference velocity) and the knowledge of profile function of velocity with respect to the height $z$, knowing reference velocity. Here, for simplicity and conservative computations, the distribution of all sectors is assumed to represent the most critical wind direction North-West. The distribution of reference wind velocity $(10 \mathrm{~m}$ height), deduced from data collected during 33 years, for all direction is plotted in Figure 9 for the site of Saint-Nazaire.

We select a Weibull distribution [2], which fits the distribution tail quite well; this is of major importance because this part of distribution represents extreme values and governs the reliability level.

$$
f(x)=\frac{k}{x}\left(\frac{x}{A}\right)^{k} \exp \left[-\left(\frac{x}{A}\right)^{k}\right]
$$

Where $A$ is the scale parameter and $k$ is the shape parameter (here $A=21.1 \mathrm{~m} / \mathrm{s}$ and $k=2.13$ ). To determine the kinematics field of wind velocity $\bar{U}_{z}$ indexed by height $\mathrm{z}$, the law [3] is used (CSTB, 1995).

$$
\frac{\bar{U}_{z}}{\bar{U}_{r e f}}=\left(\frac{z}{z_{r e f}}\right)^{r g}
$$


Where $\bar{U}_{r e f}$ is the reference velocity at reference height $\mathrm{z}_{\text {ref }}=10 \mathrm{~m}$ and $\mathrm{rg}$ is an exponent depending on site roughness; for this clear site, $r g=0.16$.

Then the resultant of loading applied by wind on one-dimension structural component between nodes $\mathrm{N}$ and $\mathrm{P}$ is given by [4].

$$
F=\left(S C_{X}\right)_{\alpha} \int_{N}^{P} p d z \text { with } p=\frac{1}{2} \rho U_{z}^{2}
$$

where $S$ is the projected area of component cross section onto the wind direction, $C_{x}$ the drag coefficient, $p$, the wind pressure, $\alpha$ the wind direction versus wharf axis (here $45^{\circ}$ ), and $\rho$ the air density $\left[\mathrm{kg} / \mathrm{m}^{3}\right]$. The term $\left(S C_{x}\right)_{\alpha}$ is expressed [5] according to (Eden, 1985).

$$
\left(S C_{x}\right)_{\alpha}=\left(S C_{x}\right)_{0} \cos ^{v} \alpha+\left(S C_{x}\right)_{90} \sin ^{v} \alpha
$$

where $v=1,\left(S C_{x}\right)_{0}$ and $\left(S C_{x}\right)_{90}$ correspond respectively to the wind direction parallel $\left(\alpha=0^{\circ}\right)$ and perpendicular $\left(\alpha=90^{\circ}\right)$ to the wharf axis $\left(\overrightarrow{e_{x}}\right)$ (see Figure 3$)$. Figure 10 gives a view of the simplified geometry for the finite element model of the crane and presents two values of these coefficients for $\alpha=45^{\circ}$. Several data of the nodes positions, related components and $\left(S C_{X}\right)_{45}$ are given in Table 1 . The crane is 63 meters high overall, the jib, 40 meters long and the distance between legs $d$ is about 20.8 meters. The deduced intensity distribution of the wind loading projected onto wharf plane is plotted in Figure 9.
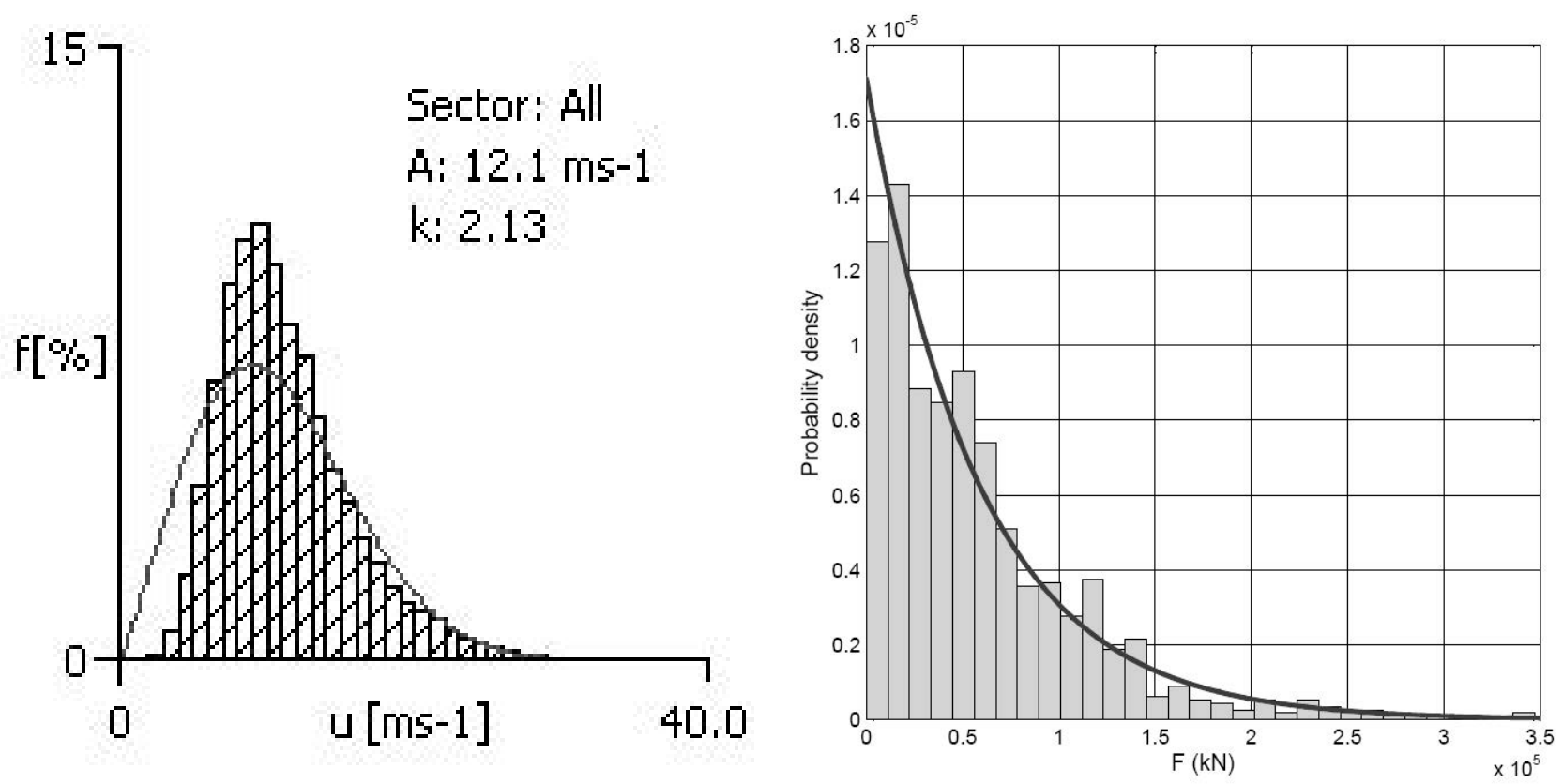

Figure 9. Distribution of reference wind velocity and histogram of the wind loading intensity $\mathrm{F}(\mathrm{kN})$ in the horizontal plan 


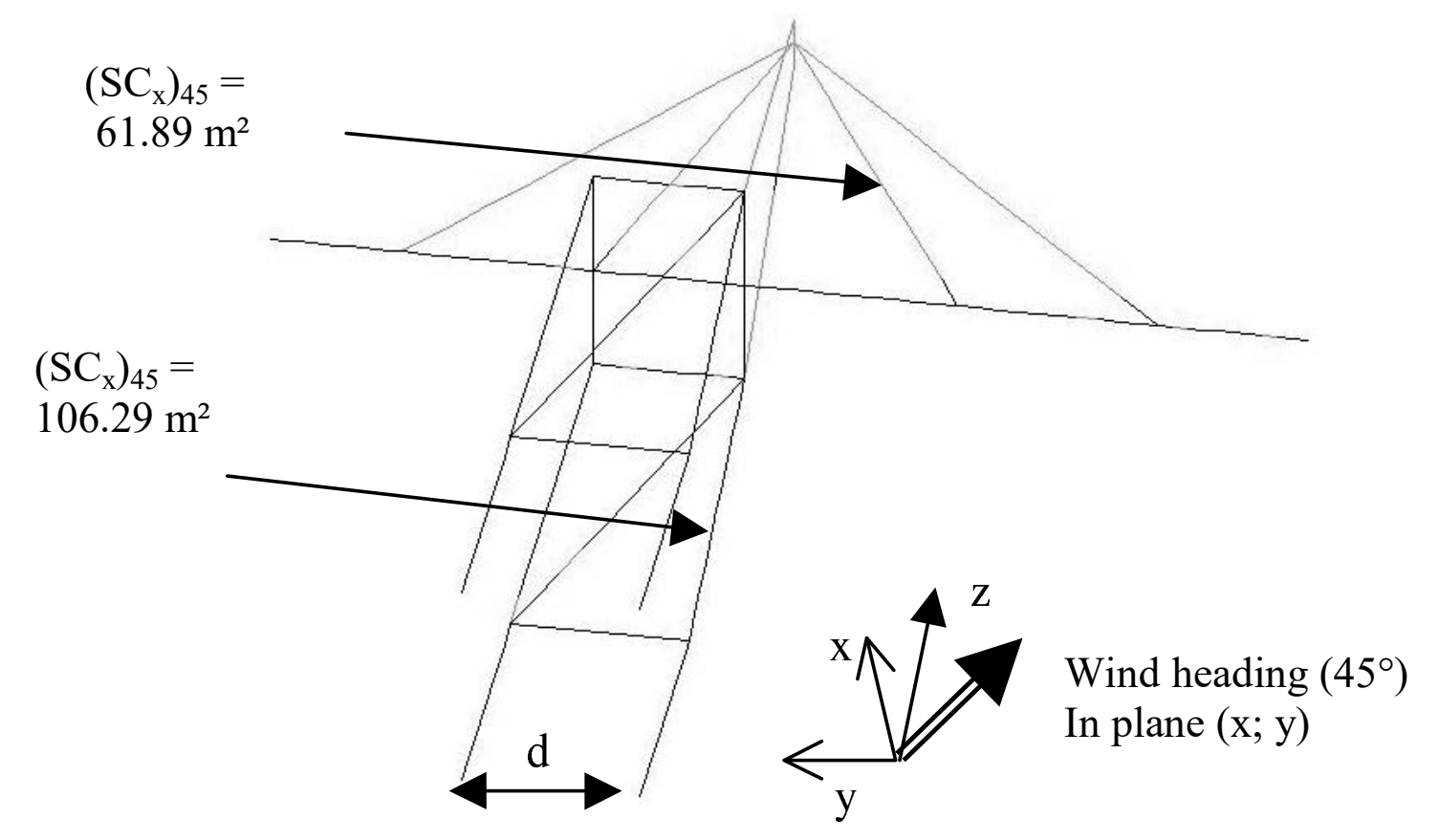

Figure 10. Model of the crane

Table 1. Nodes coordinates properties and definition of the beams

\begin{tabular}{|c|c|c|c|c|c|c|c|c|}
\hline \multirow[b]{2}{*}{$\begin{array}{l}\text { Node } \\
\text { number }\end{array}$} & \multicolumn{3}{|c|}{ Nodes coordinates [m] } & \multicolumn{2}{|c|}{ Connections } & \multirow{2}{*}{$\begin{array}{l}\text { Dimension of } \\
\text { square } \\
\text { section }[\mathrm{m}]\end{array}$} & \multirow[b]{2}{*}{$\mathrm{SCx}_{0}$} & \multirow[b]{2}{*}{$\mathrm{SCx}_{90}$} \\
\hline & $X$ & $\mathrm{y}$ & Z & $\begin{array}{c}1^{\text {st }} \\
\text { node }\end{array}$ & $\begin{array}{c}2^{\text {nd }} \\
\text { node }\end{array}$ & & & \\
\hline 1 & 29.50 & 0 & 20.80 & 1 & 3 & 1 & 65.81 & 30.88 \\
\hline 2 & 45.75 & 0 & 20.80 & 2 & 4 & 1 & 65.81 & 30.88 \\
\hline 3 & 29.50 & 15 & 20.80 & 3 & 4 & 1 & 3.90 & 84.22 \\
\hline 4 & 45.75 & 15 & 20.80 & 3 & 5 & 1 & 109.69 & 40.63 \\
\hline 5 & 29.50 & 40 & 20.80 & 3 & 6 & 0.1 & 4.20 & 21 \\
\hline \multicolumn{9}{|l|}{$\ldots$} \\
\hline 16 & 43.25 & 40 & 10.40 & 14 & 15 & 1 & 3 & 82.5 \\
\hline 17 & 62.75 & 40 & 10.40 & 15 & 16 & 1 & 7.2 & 144.5 \\
\hline 18 & 81 & 40 & 10.40 & 16 & 17 & 1 & 3 & 84.70 \\
\hline \multicolumn{9}{|l|}{$\ldots$} \\
\hline \multirow[t]{3}{*}{22} & 40.827 & 63.125 & 12.90 & 21 & 22 & 0.4 & 9.87 & 0 \\
\hline & & & & 11 & 15 & 1 & \multicolumn{2}{|c|}{$\begin{array}{l}\text { Protected against } \\
\text { wind }\end{array}$} \\
\hline & & & & 15 & 5 & 1 & \multicolumn{2}{|c|}{$\begin{array}{l}\text { Protected against } \\
\text { wind }\end{array}$} \\
\hline
\end{tabular}




\section{Mechanical modelling and inverse method}

Two mechanical models have been developed: one based on a 3D-meshind and the second equivalent to the first and based on the beam theory. Only this last one is presented here and more information concerning the first one is given in (Verdure et al., 2005). In fact, 3D- meshing leads to prohibitive time cost to perform sensitivity studies in a probabilistic way. Moreover, only the global performantial criterion is here of interest. For these reasons a simpler model, based on Timoshenko beam theory is introduced which parameters are identified from the 3D-meshing:

- the deck is modelled by a Timoshenko beam with bending stiffness $\mathrm{EI}=3.9310^{14} \mathrm{~N} \cdot \mathrm{m}^{2}$ and shear stiffness KGS $=1.1110^{11} \mathrm{~N}$, these recalculated values differ from these presented in (Verdure et al., 2005) because of a finest description of front and back beams,

- each row of piles in a horizontal plane $\left(\overrightarrow{e_{x}}, \overrightarrow{e_{y}}\right)$ is modelled by a $\overrightarrow{e_{y}}$-axis spring with stiffness $58 \mathrm{MN} / \mathrm{m}$. It is obtained from soil modulus Es adapted for each row of pile with a special care to the 3 first rows near the river which support $78 \%$ of lateral loading (Verdure et al., 2005),

- the rods remain the same as in the 3D-model, i.e. cable elements.

It allows taking the local shear effects into account which come here from mooring or transverse crane loading, due to wind. Figure 11 gives a sketch of the elements of this model.

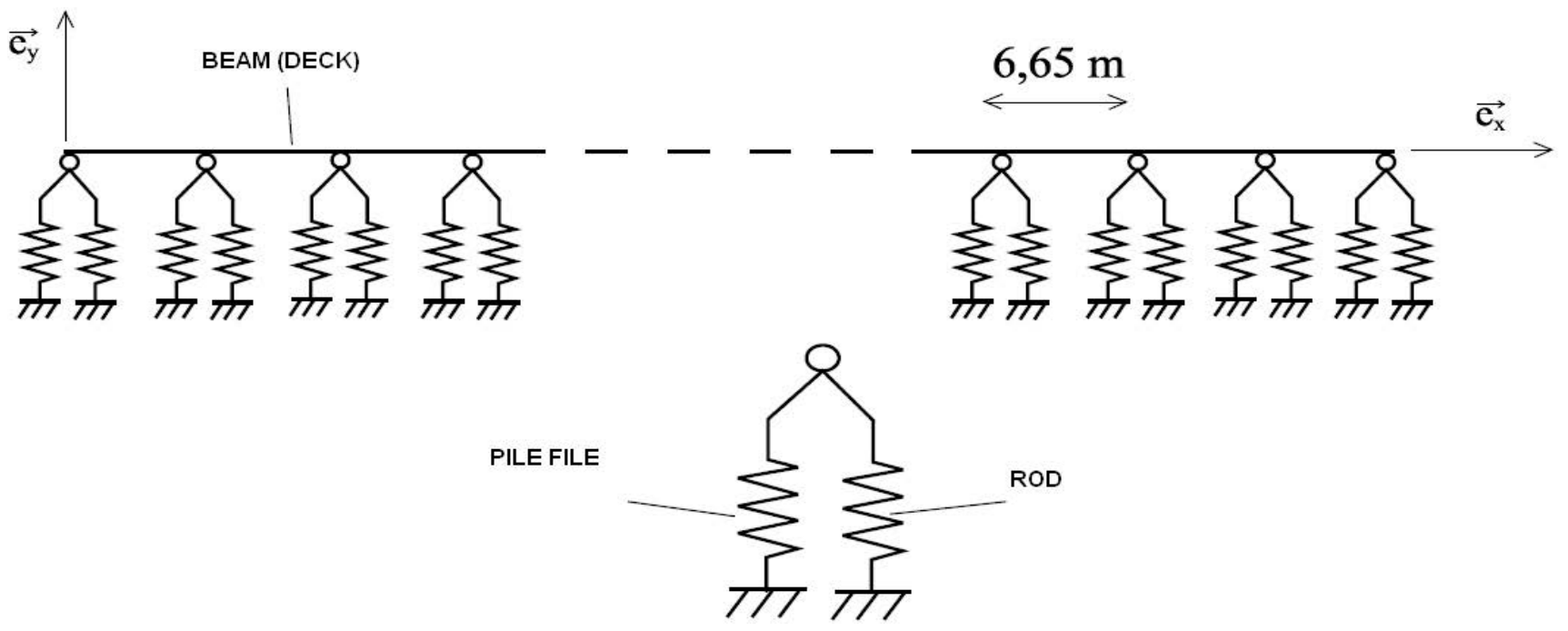

Figure 11. Equivalent beam model

Let us consider the model of the ball-joint and "soil-rod-anchorage plate". Due to the lack of in-situ data and the small size of samples, there is actually no way to give a probabilistic response model which includes parameters of soil, plate, rod and their interface. The objective is then to compute parameters of distributions for $\delta_{0}$ and $K_{t}$ which lead to output distributions presented in Figures 6 and 8. This inverse problem is solved here with a simplex optimization method (Nelder and Mead, 
1965). The algorithm is detailed and illustrated in (Verdure, 2004). Thus, optimization problem can be written as a minimization of a cost function $\lambda$, which has here a quadratic shape. The size of samples being small (38 rods), the algorithm doesn't converge on a unique solution. The solution is then considered as an average of results deduced from 100 calculations; this number results from a compromise between calculation costs and result stability. This procedure is repeated 10 times in view to evaluate a $95 \%$ confidence interval. In what follows, we consider two independent inverse analyses:

- gap $\delta_{0}$ in ball joint is identified from the distribution of loading in rods at slack tide. In this case, earth pressure due to embankment is deterministic, here $896 \mathrm{kN}$, and computed from limit analysis (Soubra, 2002). Sensitivity studies performed in (Verdure, 2004), show that earth pressure can be assumed to be deterministic for the structural reliability analysis. Stiffness $K_{t}$ is equal to its mean value. From statistics computed from data of loading (sea Figure 6), the percentage of unloaded rods $p_{\text {mes }}$, the mean $m_{F m e s}^{*}$ and standard deviation $\sigma^{*}$ Fmes for loaded rods, we deduce two optimization parameters, $\mathrm{m}_{\delta 0}$ and $\sigma_{\delta 0}$ (mean and standard deviation of $\delta_{0}$ ), from minimization of [6]. Percentage $p$ allows conditioning the problem. Here $p_{\text {mes }}$ is estimated at $0.51, m^{*}$ Fmes at $393 \mathrm{kN}$ and $\sigma^{*}$ Fmes at $104 \mathrm{kN}$. Results are given in Table 2.

$$
\lambda\left(m_{\delta_{0}}, \sigma_{\delta_{0}}\right)=\left(\frac{p}{p_{\text {mes }}}-1\right)^{2}+\left(\frac{m_{F}}{m^{*} F_{m e s}}-1\right)^{2}+\left(\frac{\sigma_{F}}{\sigma^{*} F_{m e s}}-1\right)^{2}
$$

- stiffness $K_{t}$ is identified from distribution of loading variation during a tide amplitude of coefficient 94 . In this case, the variation of earth pressure due to embankment is deterministic for the same reason given in the previous point, here $94 \mathrm{kN}$, and computed from limit analysis (Soubra, 2002). Gap $\delta_{0}$ is equal to 0 during this study. The cost function $\lambda$ is similar to [6] without the term with $p$. From statistics computed from data of variation of loading during a tide (see Figure 8), $m_{\text {Fmes }}$ and $\sigma_{\text {Fmes}}$, we deduce two optimization parameters, $m_{K t}$ and $\sigma_{K t}$ (mean and standard deviation of $K_{t}$ ). Here $m_{F m e s}$ is estimated at $35.2 \mathrm{kN}$ and $\sigma_{F m e s}$ at $21.9 \mathrm{kN}$. Results are given in Table 3.

Table 2. Solution of the inverse problem for the ball-joint

\begin{tabular}{|c|c|c|c|}
\hline Parameter & Mean $[\mathrm{mm}]$ & Standard deviation $[\mathrm{mm}]$ & $95 \%$ confidence level $[\mathrm{mm}]$ \\
\hline$m_{\delta_{0}}$ & 13.5 & 0.22 & {$[13.3 ; 13.7]$} \\
\hline$\sigma_{\delta_{0}}$ & 3.7 & 0.15 & {$[3.5 ; 3.8]$} \\
\hline
\end{tabular}


Table 3. Solution of the inverse problem for the stiffness

\begin{tabular}{|c|c|c|c|}
\hline Parameter & Mean $[\mathrm{kN} / \mathrm{m}]$ & Standard deviation $[\mathrm{kN} / \mathrm{m}]$ & $95 \%$ confidence level $[\mathrm{kN} / \mathrm{m}]$ \\
\hline$m_{K_{t}}$ & 35.6 & 0.27 & {$[35.4 ; 35.8]$} \\
\hline$\sigma_{K_{t}}$ & 23.5 & 0.48 & {$[23.2 ; 23.8]$} \\
\hline
\end{tabular}

We obtain realistic values and direct Monte-Carlo simulations have shown that the loading distributions are well described (Verdure, 2004).

\section{Reliability analysis}

Characteristics of random variables come from inverse analysis presented in the previous section. The limit state is performential: $G=U_{\max }-U_{c}$, where $U_{\max }$ is the maximum displacement along the wharf and $U_{c}$ the critical or acceptable displacement, here equal to $0.015 \mathrm{~m}$ (owner requirement). The probability of plastic collapse of rods being less than $10^{-9}$, it is not considered here. Loading of crane are located at the end of wharf. Monte-Carlo simulations are then performed using the Timoshenko beam model; we deduce a probability of failure of about $1.510^{-1}$ during 30 years. The level is slightly upper to admissible probability of fail considered in Euronorms for service limit states. Without wind effect, it falls to $7.810^{-2}$. We notice that there were not severe storm event during the monitoring time: no correlation and a finer mechanical model (non linear effects) in presence of storm can be actually developed on this basis. We present in Table 4 a sensitivity analysis for the probablity of failure to the critical displacement $U_{c}$. We note a great effect of the choice of this critical value which must then be justified with care; when increasing the critical value of $6 \%$ (from 15 to $16[\mathrm{~mm}]$ ) probability of failure decreases with a ratio up to 400 (from $1.610^{-1}$ to $3.610^{-4}$ ). Computations have been performed with values of bending stiffness EI and shear stiffness KGS selected in (Verdure et al., 2005) (see section 4) and give similar level of $\mathrm{P}_{\mathrm{f}}$ : the gap is less than $10 \%$.

Table 4. Sensibility study of the failure probability to the critical displacement

\begin{tabular}{|c|c|c|c|c|c|c|}
\hline $\mathrm{U}_{\mathrm{c}}[\mathrm{mm}]$ & 15 & 15.2 & 15.4 & 15.6 & 15.8 & 16 \\
\hline $\mathrm{P}_{\mathrm{f}}$ & $1.610^{-1}$ & $610^{-2}$ & $210^{-2}$ & $5.910^{-3}$ & $1.810^{-3}$ & $3.610^{-4}$ \\
\hline
\end{tabular}




\section{Conclusions}

This paper presents a reliability computation of a port structure. It focuses both on storm loading probabilistic modeling and on the use of monitoring data to update boundary conditions. Simplex method is used to identify the model parameters of the "soil-rod-anchorage" behaviour. After building and technological analysis two parameters are shown to be relevant: stiffness of this "soil-rod-anchorage" and gap in the ball-joint. Then the probability of failure, based on a performantial criterion (maximum wharf displacement), is deduced using Monte-Carlo simulations and simple structural model. The effect of storm is shown to have a great contribution on probability of failure and with the critical displacement selected, the probability obtained is considered as acceptable. Sensitivity study illustrates the sensitivity of the level of probability of failure to the choice of critical value; further studies should find a robust justification of this value still based on expert judgment.

\section{Acknowledgement}

This work has been carried out with both the financial support of the European Community (FEDER funds) within the Interreg III B program "Atlantic region" called MEDACHS (Marine Environment Damage to Atlantic Coast Historical and transport Structures and buildings: methods of assessment and repair, maintenance) and by a CONACyT-SFERE PhD studentship (Mexico). The authors would like to thank Harbour Authorities of Nantes St Nazaire, for their technical support and expert judgement and Mustapha Rguig and Dimitri Voisin for their contribution.

\section{Bibliography}

CSTB, Traité de physique du bâtiment, Tome 1: connaissances de base, Centre Scientifique et Technique du Bâtiment, 1995.

De Grave P., Validation partial safety factors from "probabilistic analysis sheet pile constructions (IGWR)", Delft University of Technology, Delft and Rotterdam Public Works, Section Harbours and Waterways, Rotterdam, 2002.

Eden J.F., Butler A.J. and Patient J., "A new approach to the calculation of wind forces on latticed structures", The Structural Engineer, Building Research Institute, vol. 63A, n 6 , June 1985.

Gattermann J., Bergs T., Rodatz W., "Modified instrumentation and results of stress and deformation monitoring at the new quay wall construction - Container Terminal Altenwerder, Port of Hamburg", $8^{\text {th }}$ International Conference on Structural Safety and Reliability - ICOSSAR 2001, Newport Beach, California, USA, Corotis et al. publishers, June 2001, p. 17-21.

Nelder J., Mead R., “A simplex method for function minimization”, The computer journal 7, 1965. 
Schoefs F., Surface de réponse des efforts de houle dans le calcul de fiabilité des ouvrages, PhD Thesis, Université de Nantes, 1996.

Soubra A.H., Macuh B., "Active and Passive earth pressure coefficients by a kinematical approach", Geotechnical engineering 155, $\mathrm{n}^{\circ}$ 2, April 2002, p. 119-131.

Verdure L., Cadre statistique du suivi en service des ouvrages de génie civil: application à un quai sur pieux, PhD Thesis, Université de Nantes, 2004.

Verdure L., Casari P., Wielgosz C., "Joint use of instrumentation and probabilistic modelling applied to a container wharf", Proc. $9^{\text {th }}$ Inter. Conf. on Applications of Statistics and Probability in Civil Engineering, ICASP 9, San Francisco, USA, 2003.

Verdure L., Casari P. Schoefs. F., "Analyse des mesures d'efforts dans les tirants d'ancrage passifs d'un quai sur pieux", VIII Journées génie civil-génie côtier, session posters, Compiègne 7-9 septembre, Centre français du littoral, Centre d'études techniques maritimes et fluviales, Université de Technologie de Compiègne, 2004.

Verdure L., Schoefs F., Casari P., Yáñez-Godoy H., "Uncertainty updating of an on-pile wharf after monitoring", $9^{\text {th }}$ International: conference on structural safety and reliability, ICOSSAR 2005, Rome, Italy, Augusti et al. publishers, June 2005, p. 1347-1354.

Yáñez-Godoy H., Identification d'indicateurs de performance d'un quai d'accostage en estuaire, mémoire de DEA, Université de Nantes, 2004. 